\title{
O destinatário inscrito na exposição Biomas, do Catavento Cultural
}

\author{
Arlete Machado Fernandes Higashi \\ Universidade de São Paulo (USP), São Paulo, São Paulo, Brasil \\ arlete higashi@hotmail.com \\ http://orcid.org/0000-0001-5961-9009
}

DOI: $\underline{\text { http://dx.doi.org/10.21165/el.v47i3.1974 }}$

\begin{abstract}
Resumo
O objetivo deste artigo é apresentar, do ponto de vista linguístico-discursivo, a análise dos enunciados verbo-visuais que compõem a exposição Biomas, do Catavento Cultural e Educacional, com vistas a verificar a quem os enunciados expositivos são endereçados. Para tanto, fundamentar-nos-emos no conceito de destinatário proposto por Bakhtin e seu Círculo. Os resultados preliminares apontam que a construção dos enunciados verbo-visuais da exposição Biomas leva em conta um destinatário escolarizado e afeito aos assuntos tratados e expressa ainda uma entonação enaltecedora do território brasileiro.
\end{abstract}

Palavras-chave: exposição de divulgação científica; Catavento cultural e educacional; destinatário; Círculo de Bakhtin.

\section{The recipient implied in the exhibition Biomas, from Catavento Cultural}

\begin{abstract}
The focus of this article is to present, from the linguistic discursive point of view, an analysis about the verbovisual utterances that composes the Biomas exposition, from Catavento Cultural e Educacional, in order to observe whom the expositive utterances are addressed to. For this purpose, the concept of recipient suggested by Bakhtin and his Circle will be used as basis. The preliminary results points that the construction of the verbovisual utterance of the Biomas exhibition considers an attending school recipient, more used to the subjects approached and conveys, yet, a praising entonation about the brazilian territory.
\end{abstract}

Keywords: scientific Divulgation Exposition; Catavento cultural e educacional; recipient, Bakhtin Circle.

\section{Introdução}

Diante do crescente interesse do público pelas descobertas científicas, os museus e os centros de ciências vêm passando por diversas transformações. Historicamente, na visão de Silva et al. (2002), os anos 1970, 1980 e 1990 marcaram as grandes alterações expositivas, seja no aspecto museográfico, seja nos procedimentos pedagógicos e comunicacionais. Diante disso, muitas instituições também foram criadas. No Brasil, o Museu de Astronomia e Ciências Afins/MAST, de 1985, o Museu Dinâmico de Ciências de Campinas, de 1987, o Museu de Microbiologia do Butantan, que funciona desde 2002, o Catavento Cultural, implantado em 2009, e o Museu do Amanhã, inaugurado em 2015, constituem exemplos recentes dessa expansão. Com isso, também é notório o interesse de pesquisadores e especialistas pelo estudo de museus e centros de ciências e/ou pelas suas exposições. 
Fundamentados nas mais diferentes correntes teóricas e sob as mais diversas abordagens metodológicas, as pesquisas, de modo amplo, parecem privilegiar a análise do aspecto educacional presente nas exposições e das especificidades comunicacionais em museus e centros de ciências.

Outra vertente de estudos em museu e centros de ciências diz respeito ao público visitante desses espaços. São as chamadas pesquisas de recepção que procuram, na visão de Studart et al. (2003), conhecer o público visitante e não-visitante (perfil, gostos, hábitos e características demográficas e socioeconômicas), os padrões de comportamento e interação de diferentes grupos no museu (estudantes, famílias, crianças etc.), as motivações, as expectativas e os ganhos cognitivos e afetivos. Esses trabalhos contribuem, segundo as estudiosas, para a compreensão do caráter da experiência museal, da natureza da aprendizagem nesses espaços, da influência do museu de ciências na sociedade, das práticas culturais dos frequentadores e não frequentadores e da natureza das interações sociais no contexto do museu.

Relativamente escassos são os estudos que se centram na análise discursiva dos enunciados verbo-visuais presentes em museus e centros de ciências. Estes, quando abordados, geralmente, buscam verificar as particularidades que os constituem. Chelini e Lopes (2010) assinalam que a maioria das pesquisas existentes estão voltadas para a análise das explicações de fenômenos ou objetos, ressaltando, de acordo com o tipo de instituição, os diferentes papéis que os textos exercem. Nos museus de arte, apontam as pesquisadoras citando Jacobi (1998 apud CHELINI; LOPES, 2010, p. 372), o uso de textos é reduzido, porém nos de ciências são largamente utilizados, "não só para a identificação dos espécimes, mas também na explanação de conceitos e interpretação de maquetes e reconstituições". O léxico; as estratégias linguísticas utilizadas; a seleção de informações expostas; o conteúdo explícito e implícito; o nível de compreensão de textos; o percurso de leitura, o comportamento dos visitantes diante dos textos são os elementos analisados por diversos pesquisadores, tanto dentro quanto fora do Brasil (CHELINI; LOPES, 2010). Assim sendo, na visão das autoras, a presença recorrente de textos nos museus de ciências justifica a necessidade de analisá-los, visto que seu uso é um dos principais instrumentos de comunicação museológica.

Com o propósito de contribuir tanto com os estudos de textos em museus e centros de ciências quanto com os estudos de público, o objetivo deste trabalho é realizar uma análise enunciativa-discursiva de uma das exposições de divulgação científica presentes na instituição Catavento Cultural e Educacional com vista a assinalar o(s) destinatário(s) nela presumido(s). Trata-se da exposição Biomas, da seção Vida, a qual é majoritariamente constituída por enunciados verbais e visuais distribuídos em seis grandes painéis. Além disso, a análise pretende colocar em relevo as ênfases valorativas que permeiam os enunciados e a influência que o destinatário-visitante previsto acarreta na seleção do conteúdo temático, do estilo e da construção composicional das exposições.

\section{O lugar capital do destinatário na teoria dialógica do Círculo de Bakhtin}

Ao elaborar um discurso, seja ele oral, escrito, imagético ou interior, o falante (ou escrevente) pressupõe inevitavelmente para quem ele será direcionado. E é essa imagem presumida que motivará as escolhas estilísticas, temáticas e composicionais do seu enunciado em diferentes tipos de intercâmbio comunicativo. Nesse sentido, Volochinov (2013[1930], p. 157) assinala que "cada expressão linguística das impressões do mundo 
externo, quer sejam imediatas quer sejam aquelas que vão se formando nas entranhas de nossa consciência [...], é sempre orientada para o outro", mesmo quando ele não tem existência real.

Em muitas obras de Bakhtin e seu Círculo, é possível observar a extrema relevância que o conceito de destinatário ocupa na teoria dialógica da linguagem. Em diferentes textos, Bakhtin, Volóchinov e Medviédev apresentam como correlatos à noção de destinatário os termos ouvinte, ouvinte imanente, locutor, público, povo, receptor, leitor, parceiro-interlocutor, contemplador e auditório social, destacando a importância do outro sobre o enunciado e sua conclusibilidade verbal específica.

Em O problema do texto na linguística, na filologia e em outras ciências humanas (1959-61), por exemplo, Bakhtin assinala que o outro ganha relevo no processo de interação verbal na medida em que o enunciado é considerado como uma unidade real da comunicação discursiva e é, então, o produto das relações estabelecidas entre dois ou mais interlocutores, que se alternam nos papéis de falante/escrevente/destinador e ouvinte/leitor/destinatário. Essa alternância, decorrente da interação verbal, é uma das condições para que surjam as relações dialógicas ${ }^{1}$ na medida em que elas só são possíveis entre enunciados integrais de sujeitos do discurso reais ou potenciais: "É precisamente essa comunicação dialógica que constitui o verdadeiro campo da vida da linguagem" (BAKHTIN, 2008[1963], p. 209).

De acordo com o teórico russo, as modalidades e concepções de destinatário são determinadas pelo campo de atividade humana, o que significa dizer que esse outro pode ser desde um participante-interlocutor direto do diálogo cotidiano até uma coletividade de algum campo especial da comunicação cultural, ou um outro presumido, tal como observaremos nas nossas análises. É essa concepção, mesmo que virtual, que determina o conteúdo temático, o estilo e a composição do enunciado na medida em que todo gênero discursivo tem sua compreensão de destinatário. Nas palavras de Bakhtin (2016[195253], p. 63-64)

Ao falar sempre levo em conta o fundo aperceptível da percepção do meu discurso pelo destinatário: até que ponto ele está a par da situação, dispõe de conhecimentos especiais de um dado campo cultural da comunicação; levo em conta as suas concepções e convicções, seus preconceitos (do meu ponto de vista), as suas simpatias e antipatias tudo isso irá determinar a ativa compreensão responsiva do meu enunciado por ele. Essa consideração irá determinar também a escolha do gênero do enunciado e as escolhas dos procedimentos composicionais e, por último, dos meios linguísticos, isto é, o estilo do enunciado. Por exemplo, os gêneros da literatura popular científica são endereçados a um determinado círculo de leitores dotados de um determinado fundo aperceptível de compressão responsiva [...], a consideração do destinatário (e do seu campo aperceptivo) e sua influência sobre a construção do enunciado são muito simples. Tudo se resume ao volume dos seus conhecimentos especiais.

Tais colocações mostram-se muito pertinentes para os fins deste trabalho, pois entendemos que o projeto discursivo das exposições de divulgação científica do Catavento Cultural percebe, em maior ou menor grau, um destinatário presumido, virtual, de quem também se espera um posicionamento responsivo específico. Na perspectiva

\footnotetext{
${ }^{1}$ Bakhtin (2016[1952-53]) define as relações dialógicas como relações semânticas entre toda espécie de enunciados na comunicação discursiva.
} 
bakhtiniana, mesmo as formas de exposição científica são influenciadas pela concepção de destinatário, o qual se materializa na seleção dos meios linguísticos para exprimir o endereçamento: recursos lexicais, morfológicos (pronomes, formas pessoais dos verbos), sintáticos (diversos padrões e modificações das orações) e nos elementos pictóricos.

A percepção do outro na construção do enunciado é tão importante que Bakhtin (2016[1959-61) ainda menciona a existência de um supradestinatário, entendido como um terceiro constitutivo do elo da comunicação: Deus, a verdade absoluta, o julgamento da consciência humana imparcial, o povo, o julgamento da história etc. Trata-se de uma instância superior ao destinatário presente ou próximo, cuja compressão responsiva ganha expressões ideológicas diversas, ou seja, "não se detém na compreensão imediata, mas abre caminho sempre mais e mais à frente (de forma ilimitada)" (BAKHTIN, 2016[195961], p. 105). De acordo com Amorim (2001, p. 116), toda criação se desenvolve na presença de um terceiro invisível que se situa além de seus supostos pares:

O sobredestinatário não tem nada de místico ou metafisico: ele é um momento constitutivo de todo enunciado e seu rastro pode ser identificado numa análise mais aprofundada. Na nossa interpretação, ele é aquilo que, na palavra, não estanca imediatez da enunciação e impulsiona para um adiante ilimitado.

Em Marxismo e filosofia da linguagem, Bakhtin/Volóchinov (2006[1929], p. 116117, grifos do autor) também nota a orientação do enunciado concreto em função de um interlocutor:

Qualquer que seja o aspecto da expressão-enunciação considerado, ele será determinado pelas condições reais da enunciação em questão, isto é, antes de tudo pela situação social mais imediata. [...]. A palavra dirige-se a um interlocutor: ela é função da pessoa desse interlocutor: variará se tratar de uma pessoa do mesmo grupo social ou não, se esta for inferior ou superior na hierarquia social, se estiver ligada ao locutor por laços sociais mais ou menos estreitos (pai, mãe, marido, etc.). Não pode haver interlocutor abstrato; não teríamos linguagem comum com tal interlocutor, nem no sentido próprio nem no figurado [...]. Essa orientação da palavra em função do interlocutor tem uma importância muito grande. Na realidade, toda palavra comporta duas faces. Ela é determinada tanto pelo fato de que procede de alguém, como pelo fato de que se dirige para alguém.

Nessa passagem observamos que se, de um lado, a construção do enunciado é condicionada pelo destinatário, implícito ou explícito, de outro, o contexto mais imediato (e mais amplo) também influencia no projeto discursivo do falante/escrevente, uma vez que ele determina quais serão os destinatários possíveis. Assim, na visão do autor, a situação ${ }^{2}$ também motiva a escolha do conteúdo, da forma de composição e do estilo do enunciado na medida em que "as condições da comunicação verbal, suas formas e seus métodos de diferenciação são determinadas pelas condições sociais e econômicas da época" (BAKHTIN/VOLÓCHINOV, 2006[1929], p. 160). Para o teórico russo, a

\footnotetext{
${ }^{2}$ Para Volóchinov, "a situação é a efetiva realização na vida real de uma das formas, de uma das variedades, do intercâmbio comunicativo social". (VOLÓCHINOV, 2013[1930], p. 159, grifos do autor). Isso nos remete à necessidade de considerar o contexto de produção e recepção do discurso expositivo de divulgação científica em museus e centros interativos de ciência, visto que o "querer-dizer" presente no projeto discursivo do Catavento Cultural aponta para um destinatário ativamente responsivo e inserido num contexto concreto preciso.
} 
comunicação verbal não pode ser entendida e avaliada fora do vínculo com a situação extralinguística, já que é nesse elo que se realiza a interação verbal.

De modo semelhante, a conexão entre o enunciado e o meio social circundante também foi observada por Volóchinov (2013[1926]) em Palavra na vida e a Palavra na arte, ao mencionar que o contexto extraverbal torna a palavra uma locução plena de significado para o ouvinte. Este contexto extraverbal do enunciado abrange três fatores, a saber: 1) o horizonte espacial comum dos interlocutores (a unidade do visível); 2) o conhecimento e a compreensão comum da situação por parte dos interlocutores e; 3) sua avaliação comum dessa situação ${ }^{3}$.

Para Volóchinov (2013[1926]), um enunciado concreto, de qualquer espécie, sempre será um elo entre sujeitos que conhecem, entendem e avaliam uma situação determinada. Nesse sentido, um enunciado (oral ou escrito), enquanto um todo de sentido, é, segundo o estudioso, composto por duas partes: uma verbalizada e outra subentendida. Então, "a situação forma parte da enunciação como parte integral necessária de sua composição semântica" (VOLÓCHINOV, 2013[1926], p. 79, grifos do autor).

É importante mencionar que o contexto imediato de que fala o autor pode ser mais ou menos estreito, já que tanto pode estar circunscrito à situação em que ocorre o enunciado, quanto pode se expandir no espaço e no tempo: o presumido pode ser aquele da família, da tribo, da nação, da classe social, dos dias, dos anos ou épocas inteiras (VOLÓCHINOV/BAKHTIN, 2013[1926]). À medida que se amplia o horizonte geral e seu correspondente grupo social, mais constantes se tornam os fatores presumidos em um enunciado. Quando o horizonte é mais amplo, o enunciado pode se sustentar apenas em aspectos constantes e estáveis da vida e em avaliações sociais essenciais e básicas. É nesse sentido que, a nosso ver, Medviédev (2012[1928]) destaca a dupla orientação do gênero. De acordo com o autor, qualquer enunciado se orienta de forma dupla: primeiro para o destinatário e depois para determinadas condições de realização e percepção. É essa dupla orientação que caracteriza e/ou determina o gênero de discurso. Ou seja, cada situação dispõe de um repertório específico de gêneros apropriados, os quais se adequam à comunicação social e, por conseguinte, ao destinatário do discurso:

Portanto, o direcionamento, o endereçamento do enunciado é sua peculiaridade constitutiva, sem a qual não há e nem pode haver enunciado. As várias formas típicas de tal direcionamento e as diferentes concepções típicas de destinatários são peculiaridades constitutivas e determinantes dos vários gêneros do discurso. (BAKHTIN, 2016[195354], p. 68).

Como bem revela a citação acima, a escolha dos elementos formadores do gênero do discurso é diretamente influenciada pela imagem do destinatário, seja ela real ou virtual. E é levando as considerações tecidas até aqui que nos propomos a analisar, do ponto de vista linguístico-discursivo, a inscrição do destinatário (presumido) na estrutura composicional, no estilo e no conteúdo temático que constituem os enunciados verbovisuais da exposição Biomas, do Catavento Cultural e Educacional.

\footnotetext{
${ }^{3}$ Salientamos que o autor está se referindo à interação verbal face a face, mas, conforme já exposto, no discurso escrito essa conexão também é pressuposta e representada nas dimensões verbais e visuais do enunciado.
} 


\section{Apresentação da instituição Catavento Cultural e Educacional e constituição do corpus}

Considerado o segundo museu mais visitado do estado de São Paulo, o Catavento Cultural e Educacional tem como principal objetivo veicular conhecimentos científicos de diferentes áreas do saber. Tombado como patrimônio histórico, o antigo Palácio das Indústrias serve como abrigo para cerca de 250 exposições ${ }^{4}$ que estão distribuídas em 8.000 metros. Divididas em seções, as exposições compõem quatro grandes eixos temáticos: Universo, Vida, Engenho e Sociedade. Na primeira seção, Universo, as exposições versam a respeito de assuntos relacionados ao espaço sideral e à terra. Já na segunda seção, Vida, pode-se ver a evolução do primeiro ser vivo até o homem. Na seção Engenho, apresentam-se as criações do homem dentro da ciência. E, por fim, no setor Sociedade expõem-se os problemas da convivência organizada do homem.

Durante nossas constantes visitas ao Catavento, notamos que o projeto discursivoexpositivo da instituição se materializa em recursos expográficos diversos (painéis verbovisuais, réplicas, maquetes, fotos, objetos manipuláveis, vídeos, aparelhos audiovisuais, microscópicos, observadores etc.), os quais, de modo geral, constituem o todo das exposições. No entanto, dentre esses elementos, observamos que o painel expositivo é o recurso mais utilizado para divulgar os saberes da ciência. Esses painéis são compostos pelas dimensões verbal, visual, verbo-visual e verbo-vídeo-visual. Nesse sentido, considerando que os enunciados verbais e verbo-visuais expositivos de divulgação científica constituem nosso objeto de interesse, selecionamos como corpus os enunciados que figuram nos painéis da exposição Biomas, da seção Vida, os quais apresentam saberes científicos a respeito dos seis biomas do Brasil (Pampas, Amazônia, Caatinga, Cerrado, Mata Atlântica e Pantanal), destacando aspectos relacionados ao clima, à vegetação e às espécies de animais.

A escolha do corpus se justifica por dois critérios: primeiro por ser uma exposição essencialmente formada por painéis, logo, por enunciados, objeto singular para a análise enunciativo-dialógica que empreendemos neste trabalho, ou seja, tomando emprestadas as palavras de Bakhtin (2016[1959-61], p. 87), "estamos interessados primordialmente nas formas concretas dos textos e nas condições concretas da vida dos textos, na sua interrelação e interação", e segundo, por apresentar uma extensão analítica compatível com os limites desse artigo. Isto posto, passemos à análise do corpus selecionado.

\section{O destinatário nos enunciados de divulgação científicas da exposição Biomas, do Catavento Cultural}

Levando em conta os questionamentos a quem se dirige o enunciado expositivo de divulgação científica veiculado na exposição Biomas? e Que tipo de entonação valorativa esse enunciado expositivo expressa?, procuramos voltar nosso olhar para as suas singularidades enunciativas. Assim, notamos que, nesta exposição, a forma de endereçamento do enunciado para o destinatário presumido se dá pelo diálogo velado, $\mathrm{o}$

\footnotetext{
${ }^{4}$ Entre o total de acervo, encontram-se os artefatos do MUSEUTC/CCT, cedidos em regime de comodato à instituição. Trata-se de artefatos de grande porte, que ficam na área externa da instituição, como: locomóveis que eram utilizadas na agricultura, locomotiva, aviões DC-3 bandeirante e uma carruagem, além de outros equipamentos de médio e pequeno porte que ficam expostos em diferentes pontos internos do Catavento.
} 
qual pôde ser constatado por duas categorias: 1) apagamento da expressão direta com o destinatário-visitante; 2) diretriz voltada para o objeto de discurso, conforme exposto a seguir.

Iniciamos pela estrutura composicional da exposição que, conforme já mencionado, se organiza em painéis verbo-visuais ${ }^{5}$ de grandes dimensões, criando um impacto visual no destinatário-visitante, aspecto convidativo que, a nosso ver, pode influenciar na decisão pela leitura integral dos textos:

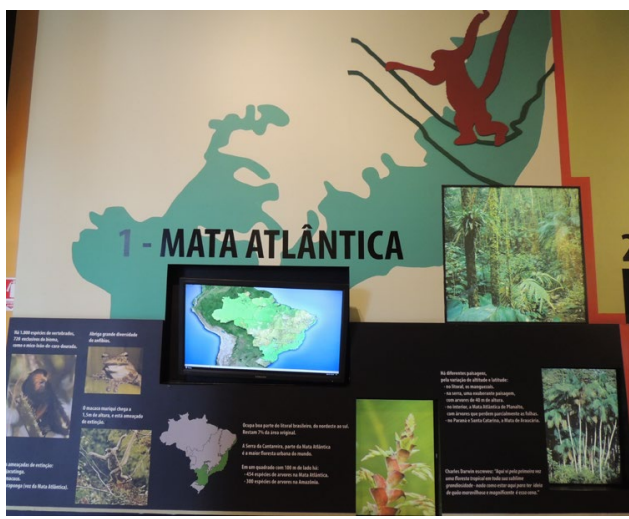

Figura 1. Painel Mata Atlântica

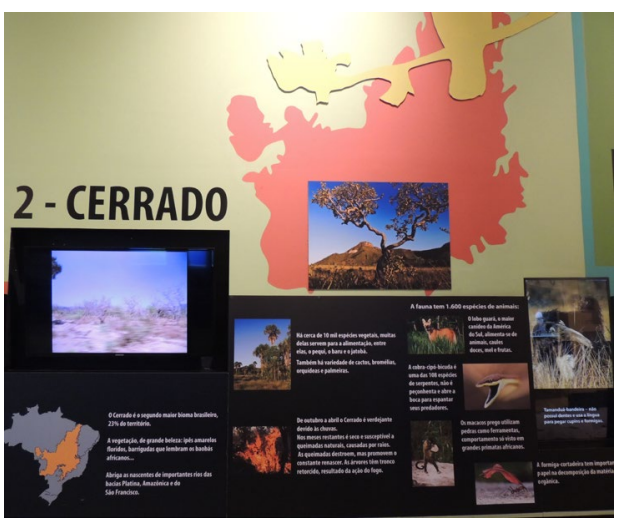

Figura 1. Painel Cerrado

Fonte: Acervo pessoal

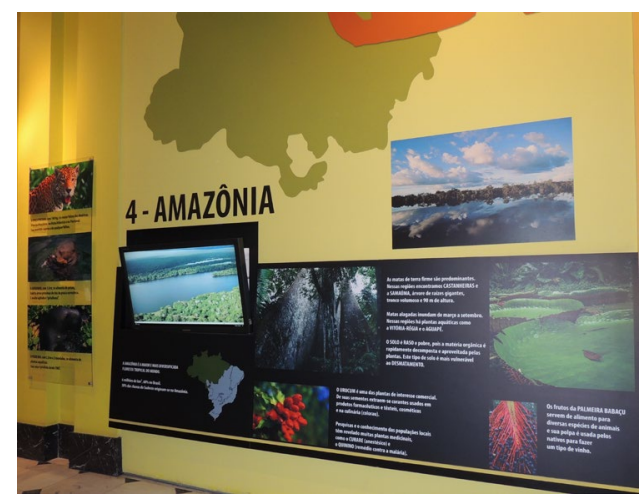

Figura 2. Painel Amazônia

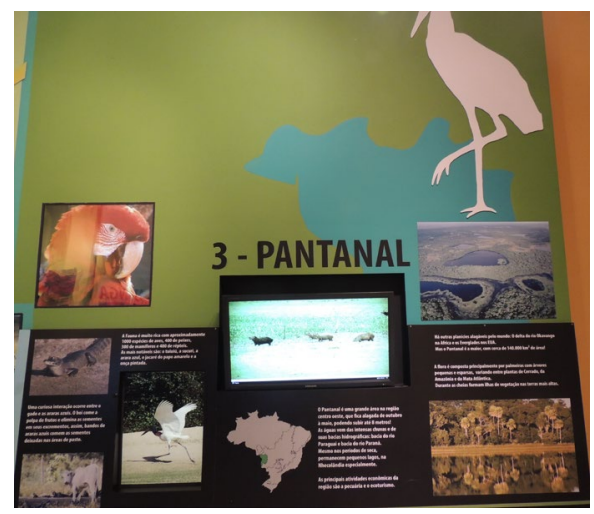

Figura 3. Painel Pantanal

Fonte: Acervo pessoal

\footnotetext{
${ }^{5}$ Além dos elementos verbais e visuais, os painéis contam com telas de TV que veiculam vídeos sobre a temática da exposição. Devido aos critérios de seleção do corpus deste trabalho, não analisaremos os vídeos que fazem parte da exposição Biomas.
} 


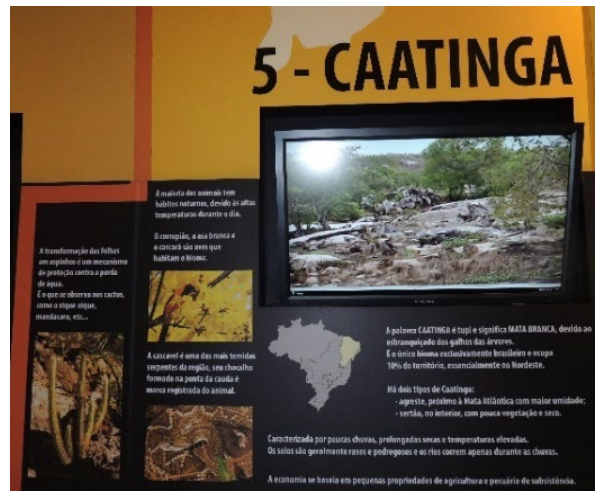

Figura 4. Painel Caatinga

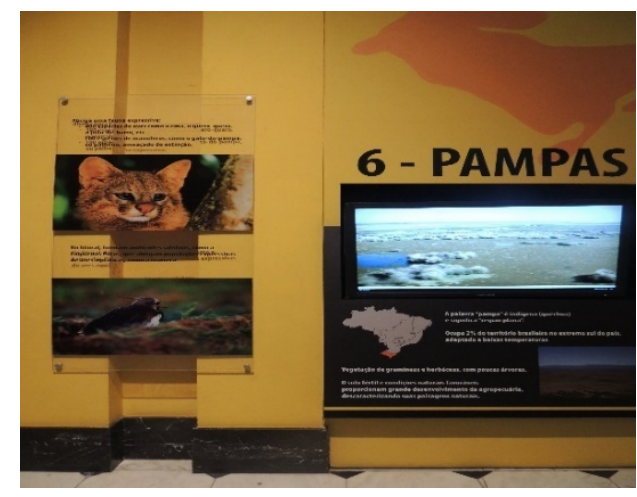

Figura 5. Painel Pampas

Fonte: Acervo pessoal

Como podemos observar, cada painel é marcado por um número que, além de sugerir um percurso de leitura para o visitante, aponta uma escala que estabelece certa hierarquia valorativa entre os biomas (Mata Atlântica, Cerrado, Pantanal, Amazônia, Caatinga e Pampas). No que tange às cores, vemos que se sobressaem os matizes vibrantes de amarelo, verde e laranja, que servem de fundo para o todo da exposição. Acreditamos que essas escolhas não são ingênuas, pois, além de delimitar os painéis e conferir amplitude e luminosidade ao espaço, a nosso ver, a mistura tem a intenção de ressaltar o direcionamento da leitura dos enunciados e representar o clima das regiões tratadas, que geralmente são mais quentes. Contrapondo-se a essa mistura, vemos que o tom preto se presta ao destaque dos enunciados escritos, bem como das imagens nele inseridas, propiciando uma maior ênfase à dimensão verbo-visual. Esses elementos contribuem, a nosso ver, para a compreensão global dos enunciados, uma vez que

$\mathrm{Na}$ compreensão efetiva, real e concreta, eles se fundem indissoluvelmente em um processo único de compreensão, porém cada ato particular tem uma autonomia semântica (de conteúdo) ideal e pode ser destacado do ato empírico concreto. 1) A percepção psicofisiológica do signo físico (palavra, cor, forma espacial). 2) Seu reconhecimento (como conhecido ou desconhecido). A compreensão de seu significado reprodutível (geral da língua). 3) A compreensão de seu significado em dado contexto (mais próximo e mais distante). 4) A compreensão ativo-dialógica (discussão-concordância). A inserção no contexto dialógico. O elemento valorativo na compreensão e seu grau de profundidade e universalidade. (BAKHTIN, 2003[1974], p. 398, grifos do autor)

A dimensão verbal se apresenta composicionalmente em tópicos centrais seguidos por explicações das espécies nativas da fauna (com destaque para os animais em extinção) da flora e do clima. Vale mencionar que, embora os painéis apresentem uma quantidade significativa de textos, os assuntos apresentam uma abordagem mais geral ${ }^{6}$, o que talvez possa ser justificado pela pressuposição de um destinatário-visitante já familiarizado com o que é exposto nos painéis, ou seja, em uma visão bakhtiniana, podemos dizer que o discurso produzido se orienta para o fundo aperceptivo do destinatário presumido, para

\footnotetext{
${ }^{6}$ Entendemos que o não-aprofundamento dos assuntos abordados se dá pelo fato de esses se aproximarem daqueles veiculados nos manuais didáticos, tornando, talvez, desnecessárias as explicações minuciosas. Dessa forma, o enunciado parece levar em conta um destinatário-visitante relativamente repertoriado, "dotado de um determinado fundo aperceptível de compressão responsiva".
} 
seus saberes anteriores, sua posição social, convicções e pontos de vista. Isso se refletirá nos demais elementos do gênero, como se verá mais adiante.

Já a dimensão visual é construída composicionalmente por fotografias de espécies de animais e de paisagens específicas dos biomas e por mapas que mostram sua localização no território brasileiro. Grillo (2013), citando Laforest (2005), menciona que a imagem feita para ilustrar um texto não se configura como uma imitação do mundo, mas como uma síntese visual do que já fora tratado no texto escrito, tal como verificamos em todos os painéis.

Assim, aliada à dimensão verbal, o que observamos é uma síntese visual de uma geografia física, cuja temática central é a descrição do meio ambiente. No entanto, não podemos deixar de notar que, a nosso ver, essa síntese é ideológica, uma vez que parece representar um Brasil que ainda não fora afetado pelas ações humanas, como as grandes queimadas criminosas, os desmatamentos, a caça predatória etc. Conti (2001), retomando Pierre George (1989), assevera que é um equívoco dar prioridade à chamada geografia física, no sentido de que o foco deve ser a localização da vida, da população, bem como a sua dinâmica relacional e conflitual com o meio ambiente.

Condizente com a estrutura composicional acima detalhada, percebemos que as escolhas estilísticas dos enunciados verbais da exposição podem ser associadas à configuração dos manuais didáticos ${ }^{7}$, visto que, além do próprio arranjo, os procedimentos linguísticos utilizados são característicos dos livros de geografia: textos curtos e objetivos, uso de conceitos seguidos de explicação, conjuntos de informações sobrepostas. O recorte de um dos tópicos do painel Pantanal exemplifica os mecanismos utilizados nos enunciados expositivos como um todo:

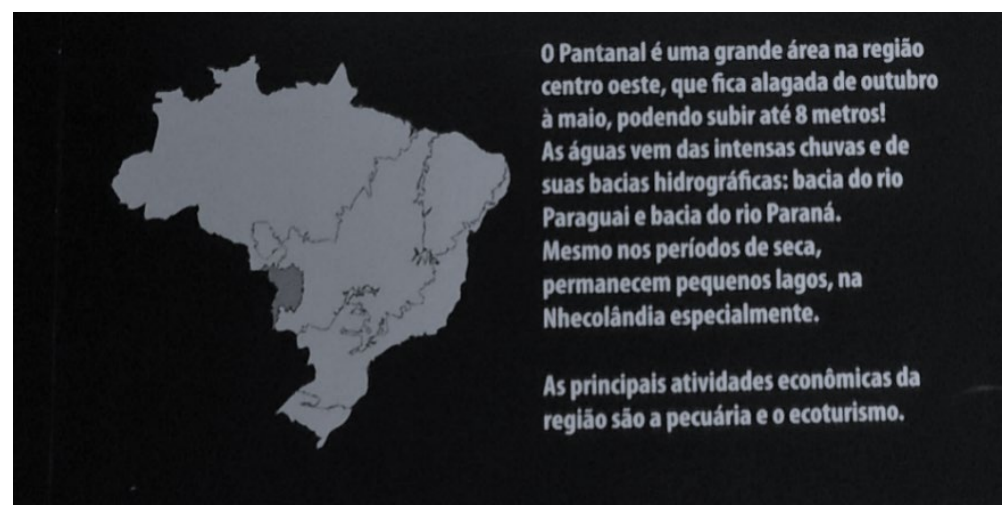

Figura 6. Excerto da exposição Biomas (Painel Pantanal)

Fonte: fotos de acervo pessoal

O excerto acima ilustra o estilo neutro que marca toda a dimensão verbal dos enunciados expositivos, o que, num primeiro momento, favorece o apagamento da imagem do destinatário-visitante presumido, uma vez que sua diretriz parece estar voltada para o conhecimento científico, seu objeto de discurso. No entanto, como bem nos alertou Bakhtin (2016[1952-53] mesmo os objetivos de exposição, centrados ao máximo no seu objeto, envolvem uma determinada imagem do seu destinatário. De acordo com o autor, os estilos objetivos-neutros lançam mão de meios linguísticos não só do ponto de vista de

\footnotetext{
${ }^{7}$ Espera-se, nas palavras de Marandino (2001), que instituições culturais, como o museu, ofereçam ao público uma forma de interação com o conhecimento distanciada da escola.
} 
sua adequação ao objeto do discurso, mas também do ponto de vista dos conhecimentos anteriores do destinatário do discurso.

Dessa forma, com um olhar mais atento, é possível dizer que o estilo livresco dos enunciados que compõem a exposição Biomas prevê um segmento de destinatáriovisitante relativamente acostumado às escolhas fraseológicas, lexicais e à objetividade que compõem os discursos presentes nos manuais didáticos, como atesta um trecho retirado de um apostilado Anglo cuja temática é a mesma do excerto acima analisado:

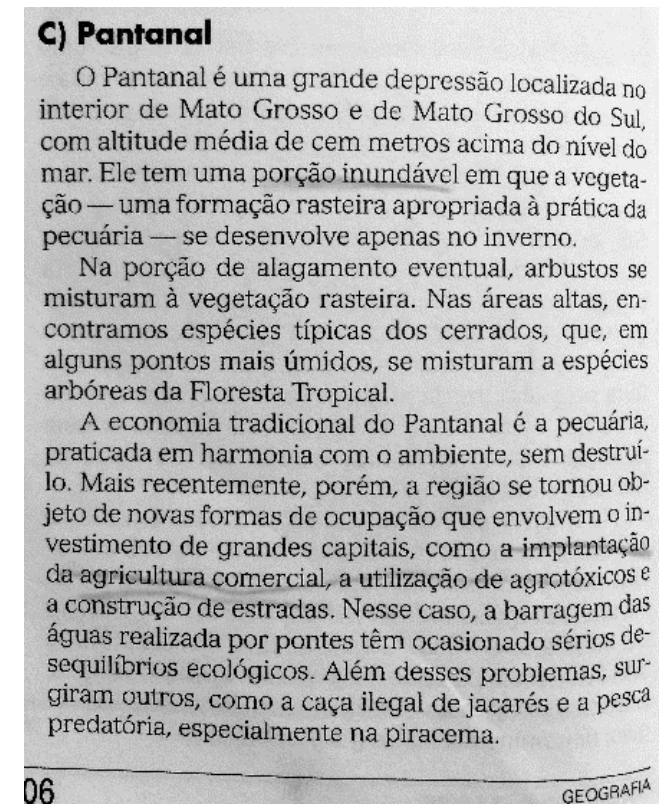

Figura 7. Excerto da apostila Anglo: ensino livro-texto (Geografia)

Fonte: Moraes (et al., 2001, p. 106)

Apontamos que ambos os enunciados (Figuras 7 e 8) parecem se inserir na perspectiva da geografia tradicional que "em suas diversas versões privilegiou os conceitos de paisagem e região" (CORRÊA, 2002, p. 17). Ao voltarmos nossa atenção para os livros didáticos, observamos que esta perspectiva mais tradicional, que foca a geografia física, é mais recorrente nos apostilados do ensino privado, uma vez que nos manuais didáticos, geralmente adotados pelo PNLD, ela parece ser mais atrelada aos aspectos humanos e econômicos (Figura 9) ${ }^{8}$ :

\footnotetext{
${ }^{8}$ Essas especificidades foram observadas por nós a partir de uma breve análise de um apostilado de geografia, do sistema Anglo Vestibulares, o qual foi distribuído aos alunos em 2016 (sistema privado de ensino), e de um livro didático de geografia do Projeto Araribá, de autoria coletiva e publicado pela editora Moderna.
} 


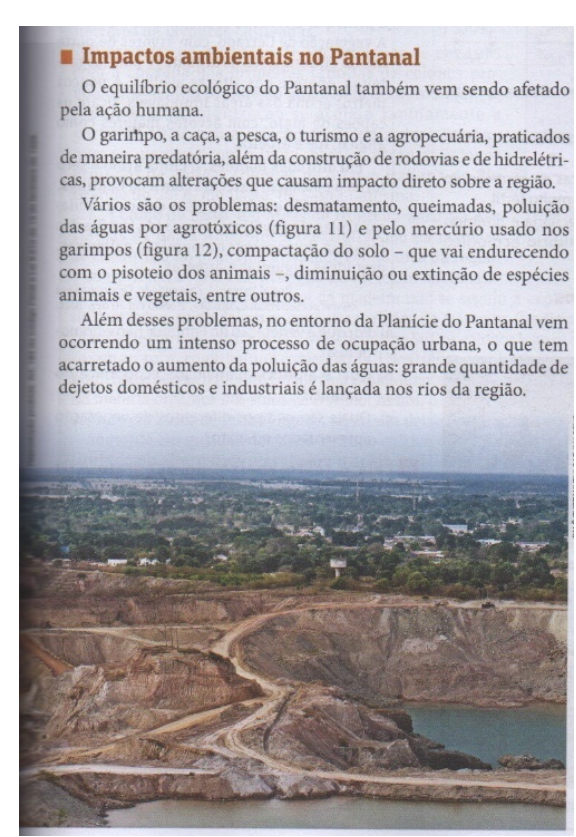

Figura 9. Excerto de livro didático de Geografia

Fonte: Projeto Araribá: geografia (obra coletiva concebida, desenvolvida e produzida pela editora Moderna, 2010, p. 197)

Dessa forma, de modo geral, a exposição espera aproximar-se do universo de referência do destinatário-visitante, o qual parece estar (ou pelo menos esteve) inserido na esfera educacional ${ }^{9}$, como o seguimento estudantil, e, indo mais além, o seguimento docente, especialmente os professores de geografia que podem recorrer à visitação com seus alunos como um reforço didático. Assim, para usar as palavras de Bakhtin (2003[1970-71], p. 383), "A modalidade da explicação e de interpretação se reduzem com muita frequência a essa descoberta do repetível, ao reconhecimento do já conhecido [...]”.

Contudo, esses saberes já conhecidos, a nosso ver, estão atrelados ao ensino de geografia do século XIX que, segundo Cavalcanti (1988), objetivava contribuir para a formação dos cidadãos por meio da difusão da ideologia do nacionalismo patriótico. Este caráter se materializa nas duas dimensões da exposição Biomas, no sentido de que as escolhas verbais e visuais constituem um querer-dizer enaltecedor dos biomas do Brasil:

(1) Painel 1: a Serra da Cantareira, parte da floresta amazônica, é a maior floresta urbana do mundo. Charles Darwin escreveu: "aqui vi pela primeira vez uma floresta tropical em toda sua sublime grandiosidade - nada como estar aqui para ter uma ideia de quão maravilhosa e magnificente é esta cena".

(2) Painel 2: a vegetação, de grande beleza: ipês amarelos floridos, barrigudas que lembram os baobás africanos.

(3) Painel 3: a fauna é muito rica.

(4) Painel 4: a Amazônia é a maior e mais diversificada floresta tropical do mundo.

(5) Painel 5: é o único exclusivamente brasileiro.

\footnotetext{
${ }^{9}$ Para Padovan (2016), as exposições de ciência alinham-se mais com os conteúdos trabalhados nas escolas do que com os saberes científicos mais atuais produzidos nas universidades.
} 
Como se vê nos enunciados acima, as escolhas lexicais são um dos recursos que servem para expressar uma relação valorativa e ideológica ante ao exposto, visto que, na exposição analisada, os saberes científicos apresentados constroem uma visão enaltecedora não apenas da biodiversidade brasileira, mas também da geografia tradicional, majoritariamente descritiva nos seus aspectos de região-paisagem, o que é corroborado pela presença do discurso de autoridade atribuído a Darwin: "aqui vi pela primeira vez uma floresta tropical em toda sua sublime grandiosidade - nada como estar aqui para ter uma ideia de quão maravilhosa e magnificente é esta cena". Nisto, pode-se dizer que a inserção da palavra do outro, linguisticamente materializado pelas aspas, espera influenciar a visão do destinatário sobre o mesmo objeto, no sentido de estabelecer com ele uma relação dialógica de concordância.

Seguindo a mesma direção do estilo da dimensão verbal, os aspectos estilísticos da dimensão visual também se assemelham, em muito, às fotografias usadas nos manuais didáticos, inclusive dialogam com elas em termos de tipos de fotos: animais típicos (geralmente em extinção) e paisagens vegetais, como atesta a comparação abaixo:

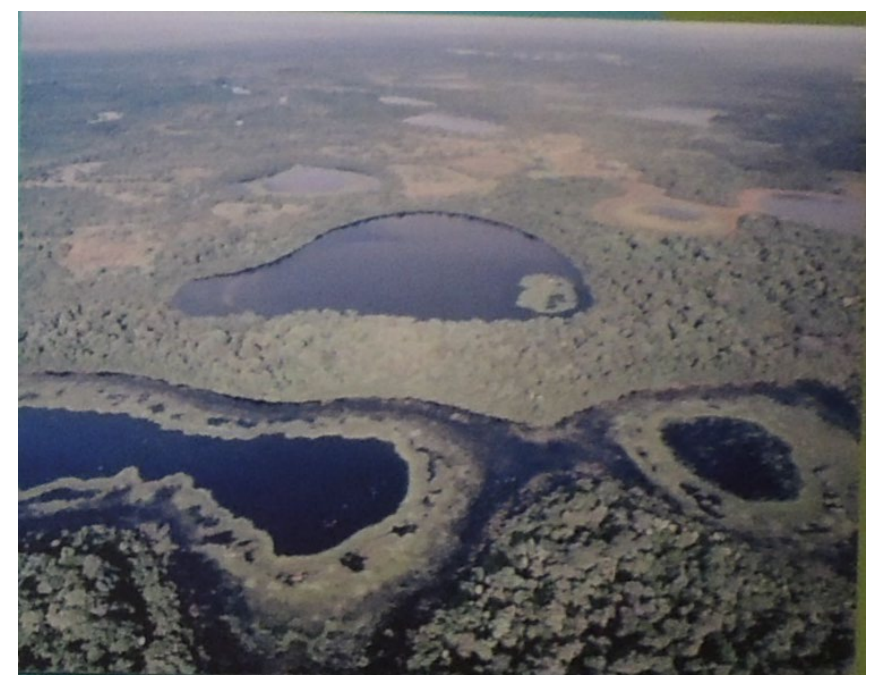

Figura 10. Excerto presente na exposição Biomas (painel Pantanal)

Fonte: Acervo pessoal 


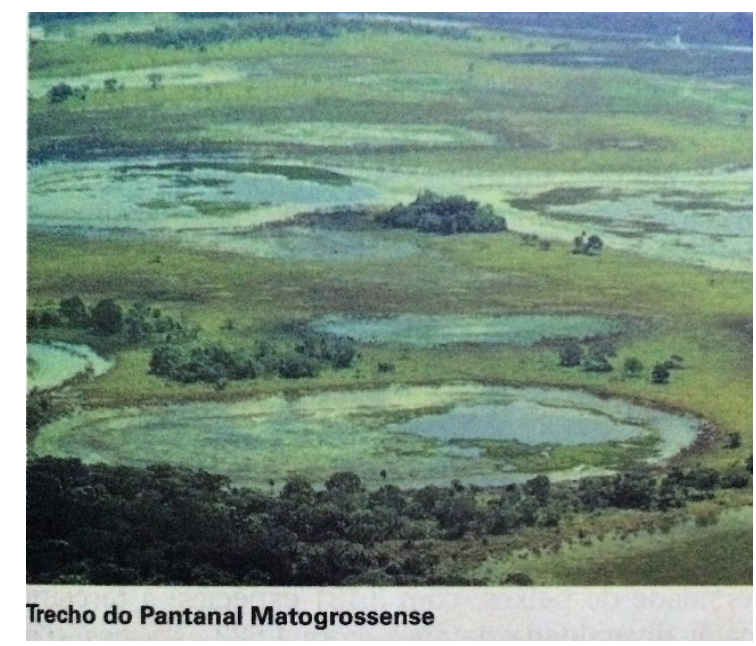

Figura 11. Excerto da apostila Anglo: ensino livro-texto (Geografia)

Fonte: Moraes (et al., 2001, p. 107)

Além disso, no todo, as imagens também refletem certa ênfase valorativa em relação ao que é abordado, uma vez que dentre os diversos animais que compõem a fauna dos biomas do Brasil, selecionaram-se aqueles que estão em extinção para figurar como representativos do lugar, bem como as classes específicas da vegetação que são usadas desde a culinária até a indústria têxtil. A nosso ver, essas escolhas também não são neutras, mas orientadas pela presunção de uma atitude responsiva de conscientização, preservação e valorização pelo visitante-destinatário. Como bem observou Bakhtin (2016[1952-53]), o falante sempre espera uma resposta, uma influência educativa, uma concordância, uma participação, uma objeção, uma execução, uma avaliação etc., por parte do destinatário.

Por fim, a escolha dos elementos composicionais e estilísticos parece colocar em relevo o conteúdo temático da exposição Biomas: a retomada e a valorização dos saberes científicos veiculados pelos manuais didáticos, com ênfase nas principais formações vegetais do Brasil e sua fauna ameaçada. No que tange ao visitante-destinatário inscrito no conteúdo temático da exposição Biomas, podemos dizer que ele se constitui de um segmento mais coletivo, como o de estudantes e professores, de quem o enunciador parece esperar uma compreensão mais contemplativa da realidade expressa, o que não se confunde com passividade, mesmo porque na teoria dialógica proposta pelo Círculo de Bakhtin, um enunciado concreto sempre é direcionado a um destinatário responsivo.

\section{Considerações finais}

O propósito da análise acima não objetivou delimitar apenas o público a partir de categorias como homem, mulher, criança, jovem, público escolar/espontâneo etc., as quais, guardada a devida importância, não revelariam a fundo a especificidade do destinatário-visitante presumido nos enunciados verbo-visuais da exposição Biomas. Ultrapassando tal finalidade, a análise exposta procurou sinalizar que a construção dos enunciados da exposição Biomas se vincula à ideia de valorizar os saberes científicos transmitidos nos manuais didáticos de perspectiva mais tradicional e de enaltecer a biodiversidade brasileira. Observamos ainda que, na totalidade dos excertos selecionados, esses enunciados parecem ser endereçados a um auditório relativamente repertoriado em 
assuntos de geografia física (mas não em geografia humana, política e econômica) e, por conseguinte, supostamente, capaz de estabelecer relações entre os enunciados expositivos e outros enunciados anteriores. Nesse sentido, é possível pensar que a função principal da referida exposição é reforçar os conhecimentos já veiculados em outros campos, como o educacional. Em síntese, esperamos ter assinalado que a seleção do conteúdo temático, da estrutura composicional e, sobretudo, do estilo que constituem as dimensões verbais e visuais da exposição é motivada por esta percepção de destinatário-visitante.

\section{REFERÊNCIAS}

AMORIM, M. O pesquisador e seu outro: Bakhtin nas ciências humanas. São Paulo: Marsa editora, 2004.

BAKHTIN, M. Os gêneros do discurso. Tradução de Paulo Bezerra. São Paulo: Editora $34,2016$.

Apontamentos. In: BAKHTIN, M. Estética da criação verbal. Tradução de Paulo Bezerra. São Paulo: Martins Fontes, 2003. p. 367-392.

Metodologia nas ciências humanas. In: BAKHTIN, M. Estética da criação

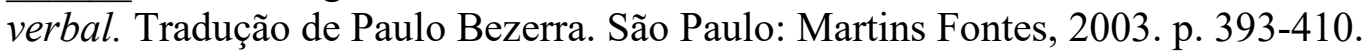

. O problema do texto na linguística, na filosofia e em outras ciências humanas. In: _. Estética da criação verbal. Tradução de Paulo Bezerra. São Paulo: Martins Fontes, 2003. p. 307-335.

. Problemas da poética de Dostoievski. Tradução de Paulo Bezerra. 4. ed. Rio de Janeiro: Forense Universitária, 2008[1963].

BAKHTIN, M./VOLÓCHINOV, V. Marxismo e filosofia da linguagem. Tradução do francês de Michel Lahud e Yara Frateschi Vieira. 12. ed. São Paulo: Hucitec, 2006[1929].

CAVALCANTI, L. S. Geografia, escola e construção de conhecimento. Campinas: Papirus, 1998.

CHELINI, M. J. E.; LOPES, S. G. B. Textos em museus de ciências: discurso científico, didático ou de divulgação? In: BENCHETRIT, S. F.; BEZERRA, R. Z.; MAGALHÃES, A. M. (Orgs). Museus e Comunicação: exposição como objeto de estudo. Rio de Janeiro: Museu Histórico Nacional, 2010.

CONTI, J. B. A geografia física e as relações sociedade-natureza no mundo tropical. In: PIANI, A.; CARLOS, A (Orgs.). Novos caminhos da geografia. São Paulo: Contexto, 2001.

CORREAA. R. L. Espaço: um conceito-chave da Geografia. In: CASTRO, P. C. C. G.; CORRÊA, R. L. Geografia: conceitos e temas. Rio de Janeiro: Bertrand, 2002.

GRILLO, S. V. C. Divulgação científica: linguagens, esferas e gêneros. 2013. 333 f. Tese (Livre-docência em Filologia e Língua Portuguesa) - Faculdade de Filosofia, Letras e Ciências Humanas, Universidade de São Paulo, São Paulo, 2013.

MARANDINO, M. O Conhecimento Biológico nas Exposições de Museus de Ciências: análise do processo de construção do discurso expositivo. 2001. 434 f. Tese (Doutorado em Educação) - Faculdade de Educação, Universidade de São Paulo, São Paulo, 2001. 
MEDVIÉDEV, P. N. O método formal nos estudos literários: introdução crítica a uma poética sociológica. Tradução de Sheila Vieira de Camargo Grillo e Ekaterina Vólkova Américo. São Paulo: Contexto, 2012[1928].

PADOVAN, T. L. Teoria crítica e indústria museal: reflexões contemporâneas para pensar as ciências e os museus do tempo presente. 2016. 384 f. Dissertação (Mestrado em Museologia) - Programa de Pós-graduação Interunidades em Museologia, Universidade de São Paulo, São Paulo, 2016.

SILVA, G.; AROUCA, M.; QUIMARÃES, V. As exposições de divulgação científica. In: MASSARANI, L.; MOREIRA, I. C.; BRITO, F. (Orgs.). Ciência e público, caminhos da divulgação científica no Brasil. Rio de Janeiro: Casa da Ciência - Centro Cultural de Ciência e Tecnologia da Universidade Federal do Rio de Janeiro, 2002.

STUDART, D. C.; ALMEIDA, A. M.; VAlENTE, M. E. Pesquisa de público em museus: desenvolvimento e perspectivas. In: GOUVÊA, G.; MARANDINO, M.; LEAL, M. C. (Orgs.). Educação e museu: a construção social do caráter educativo dos museus de ciência. Rio de Janeiro: Access, 2003. p. 129-157.

VOLÓCHINOV, V. A construção do enunciado e outros ensaios. Tradução de João Wanderley Geraldi. São Carlos: Pedro e João Editores, 2013[1930].

Palavra na vida e a palavra na poesia. Introdução ao problema da poética sociológica. In: . A construção do enunciado e outros ensaios. Tradução de João Wanderley Geraldi. São Carlos: Pedro e João Editores, 2013[1930].

\section{LIVROS DIDÁTICOS CONSULTADOS PARA COMPARAÇÃO NA ANÁLISE:}

Projeto Araribá: geografia/organizadora Editora Moderna; obra coletiva concebida, desenvolvida e produzida pela Editora Moderna; editor responsável Fernando Carlo Vedovate. 3. ed. São Paulo: Moderna, 2010. (obra em 4 v. para alunos do $6^{\circ}$ ao $9^{\circ}$ ano. Componente Curricular: Geografia).

MORAES, P. R.; SILVA, P. L.; GARCIA, H. C. Geografia 1. Anglo: ensino livro-texto - São Paulo: Anglo, 2001. (Ensino médio).

Recebido em: 17/09/2017

Aprovado em: 27/11/2017 